
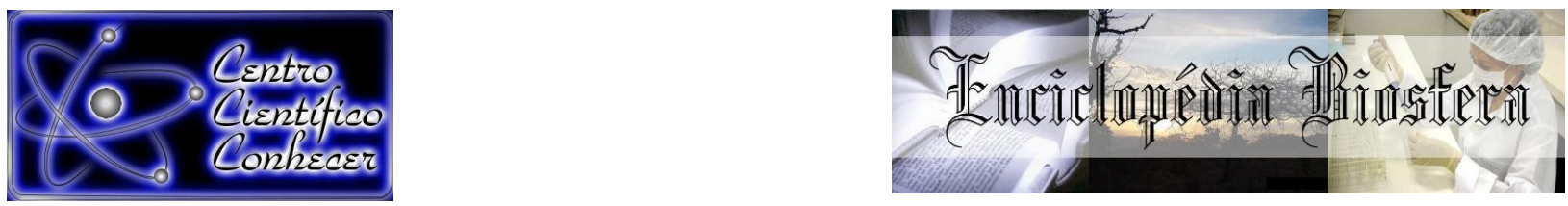

\title{
CARACTERIZAÇÃO DA VARIABILIDADE CLIMÁTICA EM DIAMANTINO/MT - BRASIL NO PERÍODO DE 1987 A 2017
}

Amanda Alves Rocha'; Jonathan Willian Zangeski Novais'르 Roberta Daniela de Souza ${ }^{3}$; Alyne Ramos de Campos dos Santos ${ }^{3}$; Valdemar Fernandes Aleixes ${ }^{1}$.

${ }^{1}$ Graduandos do curso de Engenharia Ambiental e Civil da FAEC - Faculdade de Engenharia e Computação da UNIC - Universidade de Cuiabá.

${ }^{2}$ Professor Doutor no Programa de Pós-Graduação Stricto Sensu em Ciências

Ambientais da UNIC - Universidade de Cuiabá; Cuiabá, MT.

${ }^{3}$ Mestrandas no Programa de Pós-Graduação Stricto Sensu em Ciências Ambientais da UNIC - Universidade de Cuiabá; Cuiabá, MT. E-mail: roberta.engenhariaambiental@gmail.com.

Recebido em: 06/04/2018 - Aprovado em: 10/06/2018 - Publicado em: 20/06/2018 DOI: 10.18677/EnciBio_2018A7

\section{RESUMO}

O estado do Mato Grosso é reconhecido nacionalmente como uma das principais fronteiras agrícolas do país, que depende diretamente variações atmosféricas, principalmente no que diz respeito à temperatura do ar e a quantidade de precipitação. $\mathrm{O}$ estudo teve como objetivo analisar e apresentar a variabilidade climática do município de Diamantino-MT no período de 1987 a 2017. Foram utilizados dados pluviométricos e de temperatura do ar, da série histórica de 31 anos, disponibilizados pelo Instituto Nacional de Meteorologia (INMET), que mantém uma estação meteorológica no município desde o ano de 1932. A média anual da precipitação acumulada no período foi $1791,1 \mathrm{~mm}$, em que os menores volumes médios de precipitação foram observados em julho $(10,69 \mathrm{~mm})$ e os maiores acumulados médios no mês de fevereiro $(332,72 \mathrm{~mm})$. A média anual de temperatura do ar no período em estudo foi $25,3^{\circ} \mathrm{C}$, com variações entre um mínimo de $22,6^{\circ} \mathrm{C}$, no inverno, e um máximo de $27,0^{\circ} \mathrm{C}$, na primavera. $\mathrm{O}$ período de maior concentração pluvial média ocorre de outubro a abril e o período de maior estiagem ocorre de maio a setembro. Houve aumento na precipitação acumulada anual para os últimos 15 em relação à média dos 31 anos analisados, e observou-se uma tendência de aumento de temperatura para os últimos três anos, necessitando de um acompanhamento constante destas análises para observar se este aumento permanecerá para os próximos anos, podendo causar impactos na agropecuária e conforto da população da região.

PALAVRAS-CHAVE: Mato grosso; Precipitação pluviométrica; Temperatura do ar. 


\title{
ANALYSIS AND CHARACTERIZATION OF CLIMATE VARIABILITY IN DIAMANTINO / MT - BRAZIL IN THE PERIOD FROM 1987 TO 2017
}

\begin{abstract}
The state of Mato Grosso is recognized nationally as one of the main agricultural frontiers of the country, which depends directly on atmospheric variations, mainly with respect to air temperature and amount of precipitation. The objective of this study was to analyze and present the climatic variability of the municipality of Diamantino-MT from 1987 to 2017. Rainfall and air temperature data from the historical series of 31 years were used by INMET (Instituto Nacional de Meteorologia), which has maintained a meteorological station in the municipality since the year 1932. The average annual accumulated rainfall in the period was $1791.1 \mathrm{~mm}$, in which the lowest mean volumes of precipitation were observed in July $(10.69 \mathrm{~mm})$ and the highest accumulated in the month of February (332.72 $\mathrm{mm}$ ). The annual average air temperature in the study period was $25.3^{\circ} \mathrm{C}$, with a variation between a minimum of $22.6^{\circ} \mathrm{C}$ in the winter and a maximum of $27.0^{\circ} \mathrm{C}$ in the spring. The period of greatest average rainfall occurs from October to April and the period of greatest drought occurs from May to September. There was an increase in annual cumulative rainfall for the last 15 years in relation to the average of the 31 years analyzed, and there was a trend of temperature increase for the last three years, requiring constant monitoring of these analyzes to see if this increase will remain for the years, and may have an impact on agriculture and the comfort of the region's population.
\end{abstract}

KEYWORDS: Rainfall; Air Temperature; Mato Grosso.

\section{INTRODUÇÃO}

A atmosfera terrestre é a sede de todos os fenômenos meteorológicos (PEREIRA et al., 2017). Para estudar esses fenômenos, é necessário conhecer os elementos meteorológicos, definidos como as grandezas, que caracterizam o tempo e o clima ao longo dos anos (BOUERI; LUNARDI, 2006).

O clima é a chave da configuração da vegetação, dos processos morfogenéticos, da distribuição da fauna, dos fluxos dos rios e dos suprimentos de água (NEVES et al., 2011). Segundo Ayoade (2010) o clima possui dois sistemas de classificação climáticos reconhecidos e utilizados amplamente, o primeiro deles é o sistema de Köppen (1931) baseada nas características térmicas e na distribuição sazonal da precipitação e o segundo o de Thornthwaite (1948) na qual fundamenta-se em dois índices climáticos principais (umidade e eficiência térmica). Em suma, as variáveis de temperatura do ar e as precipitações podem ser consideradas como os principais elementos climatológicos, pois indicam os níveis energéticos e as disponibilidades hídricas (ROLIM et al., 2007; CUNHA; MARTINS, 2009).

A temperatura do ar é uma das variáveis meteorológica de extrema relevância, pois desempenha um papel primordial na caracterização climática de uma determinada região, além de ser um dos elementos determinantes da distribuição e adaptação de plantas e animais, afetando diretamente os processos físicos, químicos e biológicos (BARBARISI et al., 2006). Esta variável é suscetível 
a alterações de acordo com o lugar e com o decorrer do tempo em uma determinada localidade, podendo ser influenciada por diversos fatores incluindo a quantidade de insolação recebida, a natureza da superfície, à distância a partir do corpo hídrico, relevo, ventos e correntes oceânicas (AYOADE, 2010). O conhecimento das variações de temperatura é fundamental em estudos de planejamento agrícola, bem como análises de adaptações de culturas a determinadas regiões (MEDEIROS et al., 2005).

Outra variável meteorológica é a precipitação, na qual entende-se por toda água proveniente do vapor d'água na atmosfera depositada na superfície sob qualquer forma, chuva, granizo, orvalho, neblina, neve ou geada dentre outras (PINTO et al., 2011). A quantidade de precipitação e a forma como essa se distribui são determinantes no tipo de vegetação presente em determinada região e atividade agrícola que é realizada (ANGELOCCl et al., 2002).

O estado do Mato Grosso é reconhecido nacionalmente como uma das principais fronteiras agrícolas do país. Na região conhecida como Chapada dos Parecis, a noroeste do estado localiza-se o município de Diamantino, que ocupa uma posição de destaque nacional devido sua agricultura mecanizada aplicada na produção de cana-de-açúcar, soja, algodão e sorgo (DUBREUIL et al., 2005), em conjunto com o modelo de cultivos em sequeiro. Contudo é necessário ressaltar que neste modelo, o desenvolvimento das culturas depende exclusivamente da precipitação (SOUSA; PERES, 1998).

Desse modo é evidente a estreita relação entre as práticas agronômicas e variações atmosféricas, principalmente no que tange à temperatura do ar e a quantidade de precipitação de uma região, sendo estes fatores climáticos determinantes para a escolha das espécies de vegetais mais propícias a serem cultivadas. Para tanto, é essencial conhecer a dinâmica climática de uma região e sua variabilidade, sendo assim necessário contemplar um conjunto de dados das condições atmosféricas, na qual se caracteriza pelo estado e evolução do tempo no curso de um período suficientemente longo em um determinado lugar (HUSCHKE, 1959), registrados de forma contínua por uma ou mais estações meteorológicas, durante um período de 30-35 anos, dentre os quais a análise da variabilidade é realizada junto à identificação dos tipos de tempos, definição de tendências e estabelecimento de médias (MENDONÇA; DANNI OLIVEIRA, 2007).

Diante do exposto, face à influência das condições atmosféricas no ambiente e na produção agrícola e do reduzido número de estudos que abordem a temática na região, esta pesquisa tem como objetivo investigar a variabilidade climática, por meio da análise de precipitação e temperatura do ar, durante o período de 1987 a 2017, no município de Diamantino - MT.

\section{MATERIAL E MÉTODOS}

\section{Caracterização da área de estudo}

O município de Diamantino localiza-se sob as coordenadas geográficas $14^{\circ} 24^{\prime} 31^{\prime \prime}$ de latitude Sul, 56²6'46" de longitude Oeste, e altitude de $269 \mathrm{~m}$ (Figura 1), e conforme a classificação de Köppen possui clima do tipo tropical úmido megatérmico (Aw), apresentando duas estações bem definidas, uma seca (abril a outubro) e outra chuvosa (novembro a março) (ALVARES et al., 2013). 


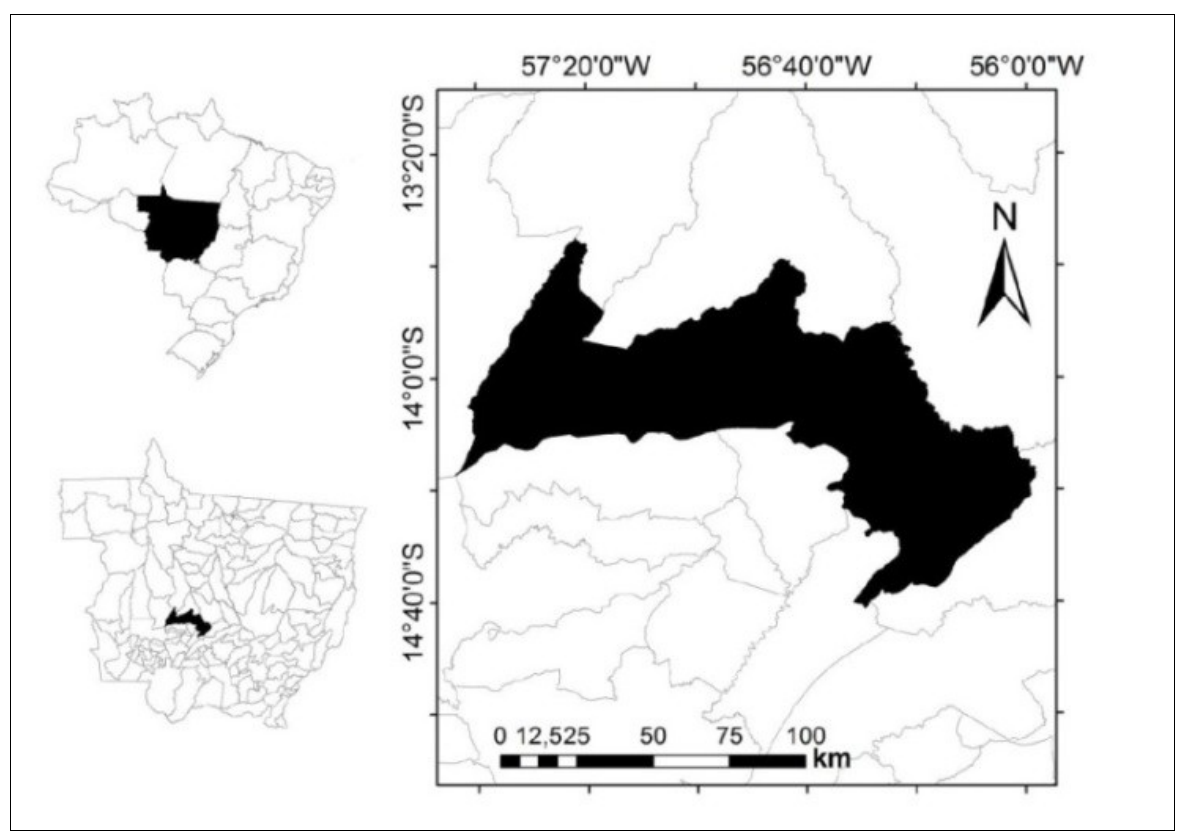

FIGURA 1 - Localização espacial do estado de Mato Grosso e do Município de Diamantino.

Fonte: Ramos et al. (2015).

Segundo o último levantamento censitário realizado e divulgado pelo Instituto Brasileiro de Geografia e Estatística (IBGE), o município de Diamantino, possui uma população de 20.341 habitantes em uma área territorial de 8.230,097 $\mathrm{km}^{2}$ (IBGE, 2010), tendo como principal atividade econômica a agricultura moderna mecanizada.

\section{Procedimentos metodológicos e interpretações estatísticas}

Para realização do estudo foram analisados dados mensais de precipitação e temperatura média compensada do ar, correspondentes ao período de observações de 1987 a 2017 (31 anos). A chamada temperatura média compensada refere-se ao cálculo realizado pelos meteorologistas nas estações meteorológicas, que consiste na média dos valores das três leituras da temperatura do ar realizadas a cada seis horas $(9 \mathrm{~h}, 15 \mathrm{~h}$ e $21 \mathrm{~h})$ mais a máxima e a mínima (BRANCO, 2014).

Os dados foram obtidos da Estação Meteorológica do Instituto Nacional de Meteorologia (INMET), locada no município de Diamantino, sob as coordenadas $14^{\circ} 4^{\prime}$ de latitude Sul, $56^{\circ} 45^{\prime}$ de longitude Oeste e altitude de $286,3 \mathrm{~m}$. Conforme INMET (2018), a estação meteorológica convencional é composta de vários sensores isolados que registram continuamente os parâmetros meteorológicos, para os registros de precipitação utiliza-se o pluviômetro tipo Ville de Paris, instalado sobre um suporte de $1,5 \mathrm{~m}$ de altura do solo, já os registros de temperatura do ar são aferidos por termômetros de mercúrio em vidro, que segundo Vianello (2011), o uso deste deve-se essencialmente à sensibilidade do mercúrio às mínimas variações da temperatura do ar, aumentando ou diminuindo de volume se o ambiente se aquece ou se resfria, ainda que ligeiramente. 
Os dados foram tabulados em planilhas eletrônicas, sendo calculados as médias e os desvios-padrão. Os gráficos foram feitos no Software Sigma Plot (SPSS, versão 11.0). Ocorreram falhas em alguns anos nas coletas de dados, estando ausentes das análises os anos de 1996 e 1997 para precipitação e os anos de 1991, 1992, 1993, 1994, 1996 e 1997 para temperatura do ar.

RESULTADOS E DISCUSSÃO

Com o intuito de observar os padrões da distribuição de precipitação e temperatura do ar, fez-se o climograma abaixo (Figura 2).

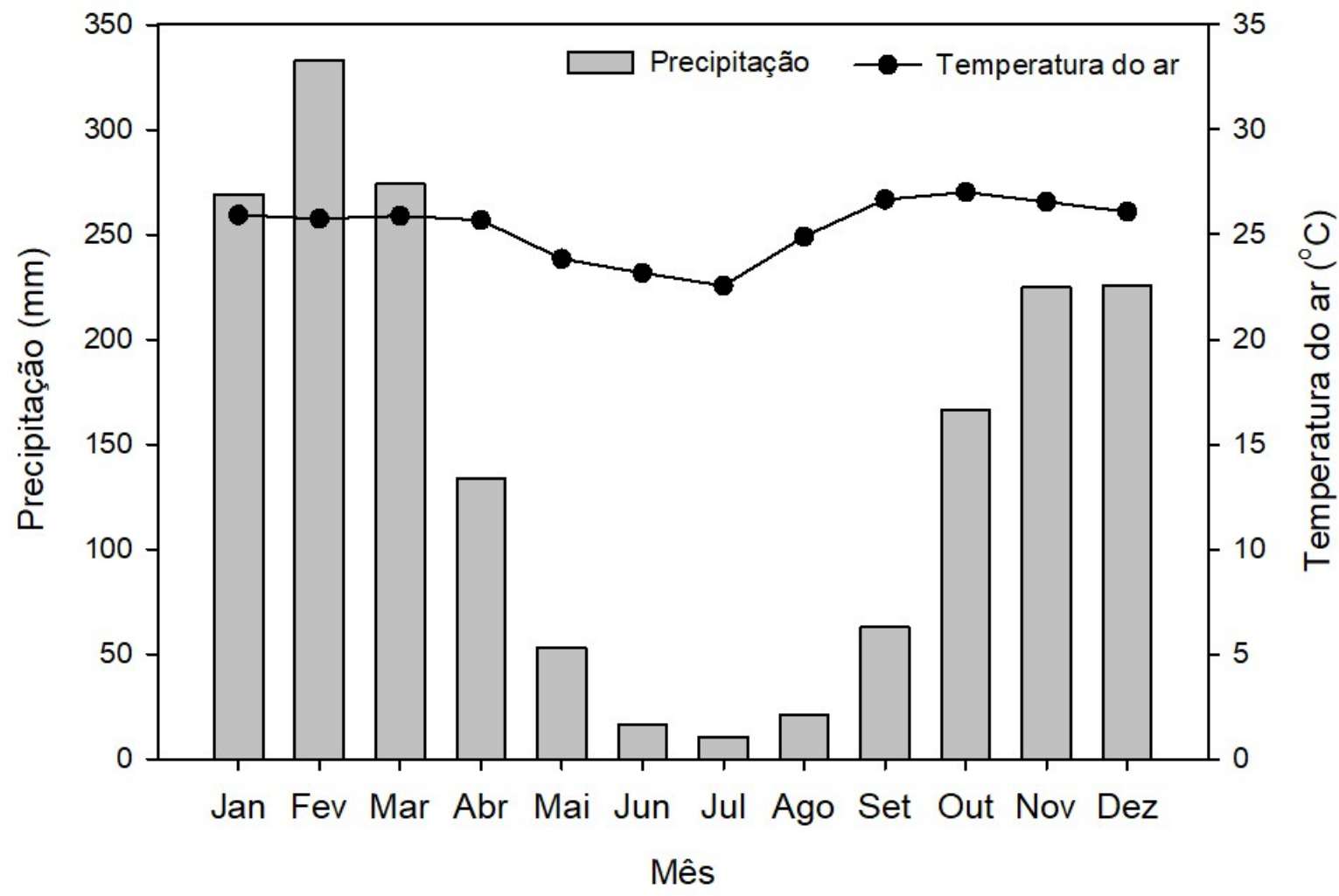

FIGURA 2 - Climograma, médias mensais da precipitação e temperatura do ar para o município de Diamantino-MT, de 1987 a 2017.

Houve grande variabilidade nos níveis de precipitação pluviométrica, sendo cada um dos níveis a representação da somatória média mensal de chuvas ocorridas durante o período avaliado (1987 a 2017). Os volumes máximos de precipitação média mensal durante o período chuvoso ocorreram nos meses de janeiro $(269,35 \mathrm{~mm})$, fevereiro $(332,72 \mathrm{~mm})$, e março $(274,07 \mathrm{~mm})$, já os menores volumes foram registrados no mês de julho, $10,69 \mathrm{~mm}$, durante estação seca (Figura 2).

O período de chuva está associado ao deslocamento para sul da Zona de Convergência Intertropical (ZIT), acompanhando a marcha aparente do sol em direção ao Trópico de Capricórnio. Sobre a porção central da América do Sul, onde localiza-se o estado de Mato Grosso, a ZIT avança mais para sul do que nas regiões costeiras gerando instabilidade em todo o Brasil central nos meses de verão. Em função da influência da massa de ar tropical marítima e equatorial, as 
temperaturas são elevadas durante todo o ano (HASENACK et al., 2003). No inverno, quando a CIT está deslocada para norte, a região apresenta baixa ou nenhuma precipitação (MARCUZZO et al., 2012).

Segundo Monteiro (1962), frequentemente a região Centro-Oeste é dominada pela massa Tropical Atlântica $(\mathrm{Ta})$ que, devido à ação do anticiclone semifixo do Atlântico Sul, tem uma atuação bastante relevante durante o ano todo. No verão, a massa torna-se inferiormente instável devido ao aquecimento basal que sofre ao entrar em contato com o continente. Durante o inverno, o resfriamento basal aumenta a estabilidade superior, contribuindo, assim, para a ocorrência de tempo estável. A massa Equatorial Continental (Ec), cujo centro de origem está na planície amazônica, é quente e de elevada umidade específica. Durante o verão, atraída pelos sistemas depressionários do interior do continente, tende a avançar do NW, ora para SE, ora para ESE, atingindo a região CentroOeste, onde provoca elevação das temperaturas, sendo responsável ainda pelo aumento da umidade e das precipitações (BARROS, 2003).

Diante da análise da figura 2, é notório o declínio progressivo da precipitação média mensal no município até o mês de maio, com registros médios inferiores a $30 \mathrm{~mm}$ para os meses de junho $(16,31 \mathrm{~mm})$, julho $(10,69 \mathrm{~mm})$ e agosto $(21,29 \mathrm{~mm})$, na qual compõe a estação seca (ALVARES et al., 2013). O desviopadrão para o mês de junho foi $17,2 \mathrm{~mm}$, julho $22,4 \mathrm{~mm}$ e agosto $31,8 \mathrm{~mm}$, caracterizando o período crítico para desenvolvimento das culturas em regime de sequeiro (DALLACORT et al., 2010).

A média anual de precipitação observada no período de 31 anos foi de $1791,1 \mathrm{~mm}$, valor próximo ao encontrado por Martins et al., (2010), que registraram $1815,5 \mathrm{~mm}$, para o município supramencionado, no período de 1961 a 2008 , caracterizando desta maneira duas fases distintas no comportamento da pluviosidade da região, uma chuvosa, de outubro a abril, passando por um período transitório de declínio dos níveis de precipitação, e outra seca entre os meses de maio a setembro seguido por período transitório de elevação nos níveis de precipitação, o que, conforme Sousa (1998) é um comportamento típico da região dos cerrados.

Com relação aos resultados de temperatura média mensal do ar obtidas a partir da série de 31 anos de dados meteorológicos no Município de Diamantino (MT), nota-se pequenas amplitudes na variação entre a média dos meses mais quentes para os mais frios. Verificou-se que as médias mensais de temperatura média do ar variaram entre $22,6^{\circ} \mathrm{C}$ em julho e $27,0^{\circ} \mathrm{C}$ em outubro, nesse período também foram observados os maiores desvios-padrão, $0,9^{\circ} \mathrm{C}, 0,8^{\circ} \mathrm{C}, 1,0^{\circ} \mathrm{C} \mathrm{e}$ $0,5^{\circ} \mathrm{C}$ respectivamente.

Resultados similares a este foram observados por Dallacort et al., (2010) em estudo realizado no município de Diamantino - MT, no período histórico de 1961 a 2008 , em que as médias mensais de temperatura do ar foram $22,6^{\circ} \mathrm{C}$ para o mês de julho e $26,5^{\circ} \mathrm{C}$ para o mês de outubro. Durante o período de estiagem entre os meses de maio a agosto registrou-se as maiores amplitudes térmicas, bem como os maiores índices de desvio-padrão, fato este decorrente da falta de água no sistema atmosférico, pois o vapor de água desempenha um efeito regulador, atenuando as amplitudes térmicas, este fenômeno é comumente observado em regiões onde o clima sofre influência da continentalidade. 
A temperatura média anual do ar no município de Diamantino não ultrapassou $25,3^{\circ} \mathrm{C}$. Os meses com temperaturas mais baixas foram: maio, junho, julho e agosto. Entretanto nos últimos quatro meses do ano a temperatura média do ar se manteve constaste aos $26,6^{\circ} \mathrm{C}$, exceto o mês de outubro, que ultrapassou a média anual de temperatura do ar, de $25,3^{\circ} \mathrm{C}$, chegando a $27,0^{\circ} \mathrm{C}$. As temperaturas elevadas durante todo o ano, observadas no Brasil central, decorrem em função da influência da massa de ar tropical marítima e equatorial (HASENACK et al., 2003).

Todavia as temperaturas médias mensais do ar foram compatíveis com as estações do ano, no decorrer do período estudado, com temperaturas baixas no outono e no inverno, assim como temperaturas mais elevadas na primavera e no verão (LIMA et al., 2011). Com o intuito de se avaliar variações anuais de precipitação calculou-se o acumulado anual conforme Figura 3.

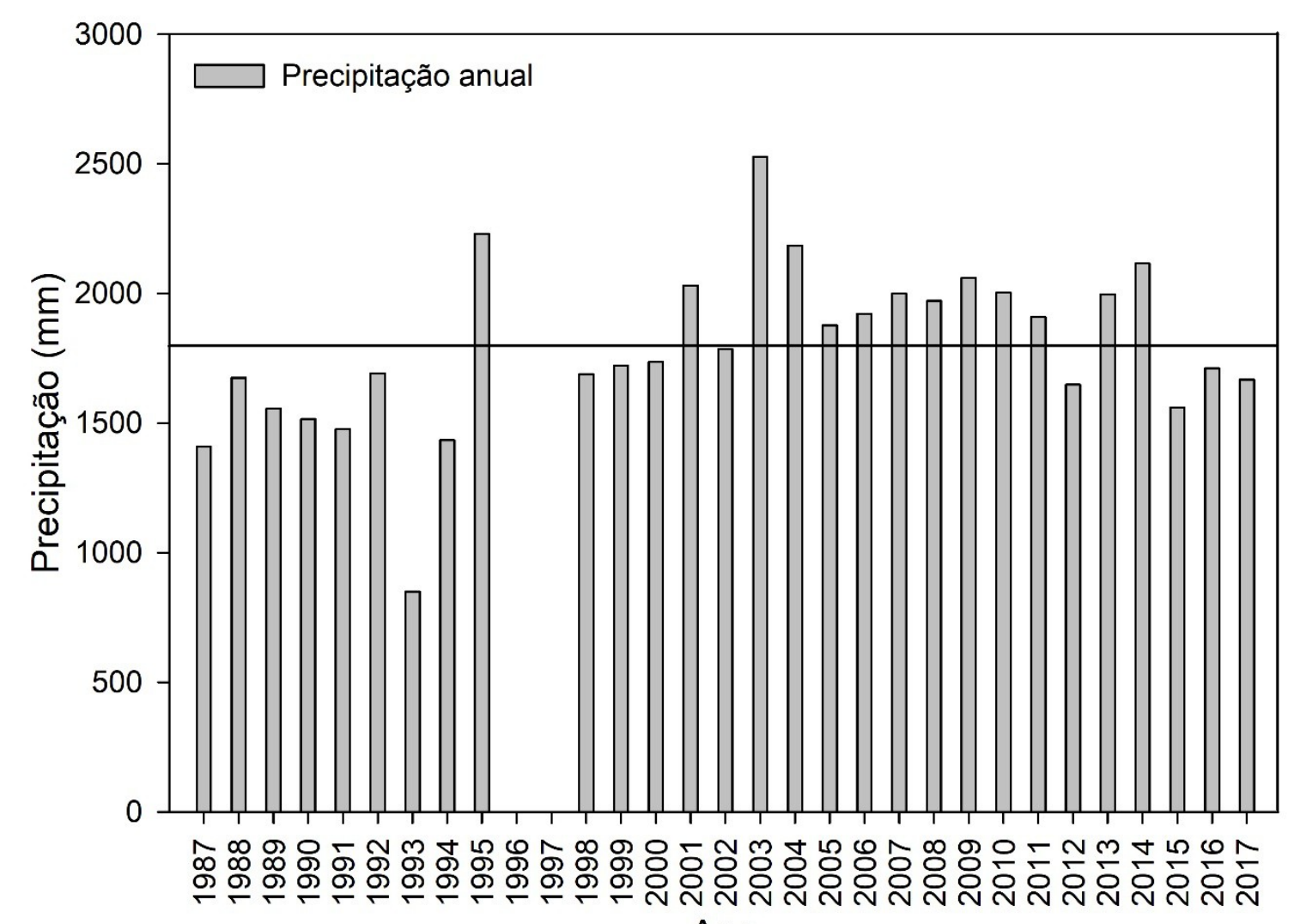

Ano

FIGURA 3 - Distribuição pluviométrica acumulada anual para o município de Diamantino-MT, de 1987 a 2017.

A média anual de precipitação para os anos analisados foi de $1791 \mathrm{~mm}$, conforme linha contínua na figura 3. Dos 29 anos analisados, não houve dados de precipitação em 1996 e 1997, 16 anos ocorreram precipitação abaixo da média (55\%) e 11 anos acima da média (45\%). Cabe salientar que dos 11 anos com precipitação acima da média, 10 ocorreram nos últimos 15 anos, mostrando uma tendência de elevação pluviométrica para Diamantino-MT. 
Conti (2005a, p. 19) ressalta que a variabilidade climática é produto tanto do espaço quanto do tempo, e a tendência nunca é igual de um ano para o outro e nem de década para década. Para o autor, é possível verificar flutuações a curto, médio e em longo prazo. Para analisar as variações médias anuais de temperatura do ar segue a Figura 4.

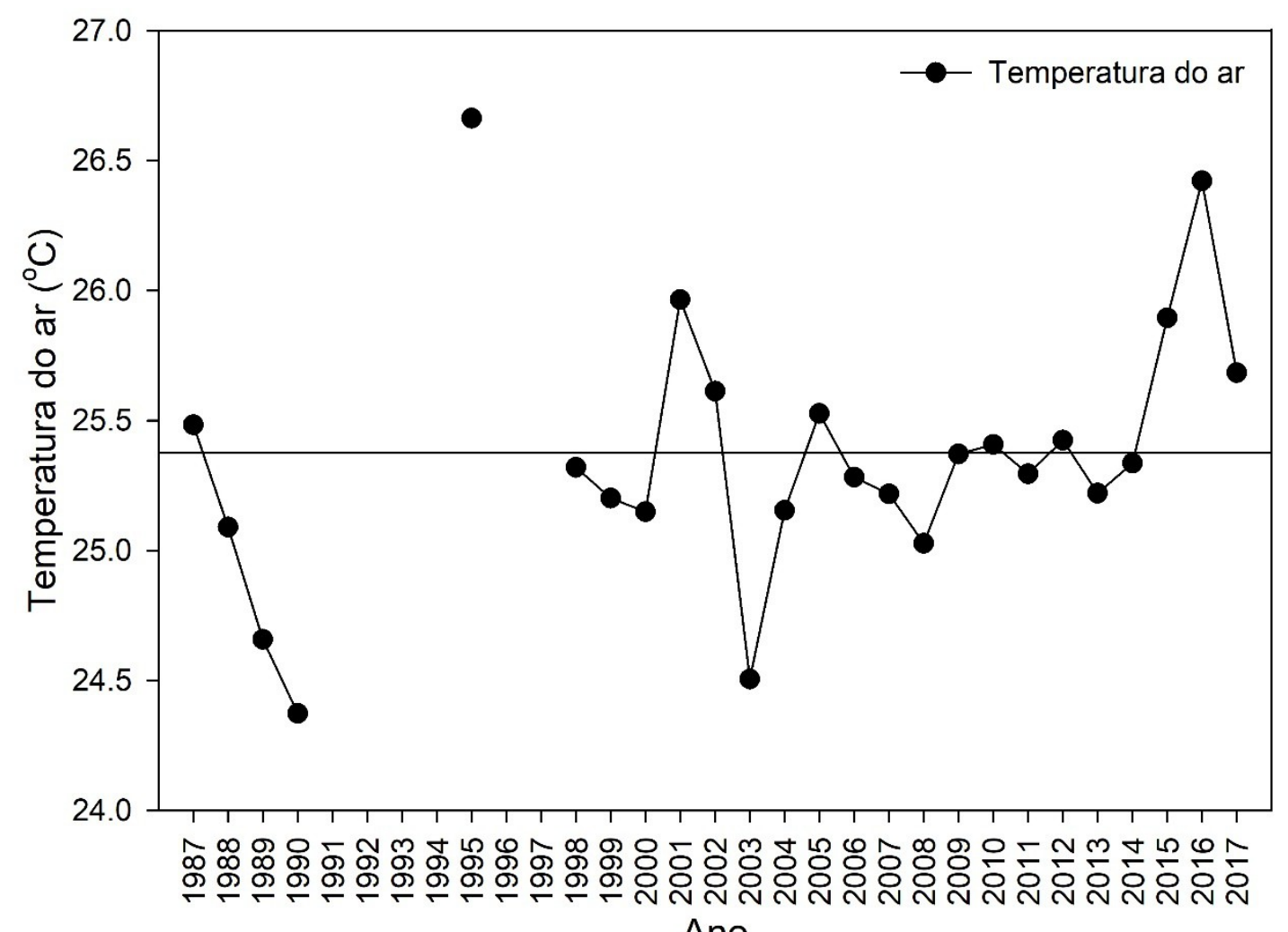

FIGURA 4- Distribuição da temperatura média anual para o município de Diamantino-MT, de 1987 a 2017.

A média da temperatura do ar para o período analisado foi $25,3^{\circ} \mathrm{C}$. $\mathrm{O}$ ano de 1990 foi o ano de menor média de temperatura do $a r, 24,37^{\circ} \mathrm{C}$, e como anos mais quentes destacam-se os anos de 1995 com temperatura do ar média de $26,66{ }^{\circ} \mathrm{C}$ e o ano de $2016 \mathrm{com} 26,42{ }^{\circ} \mathrm{C}$. Observa-se que nos últimos três anos analisados ocorreram temperaturas médias anuais maiores que a média dos 31 anos, chegando a aproximadamente $1,1^{\circ} \mathrm{C}$ de aumento para o ano de 2016, gerando ligeira preocupação de que isso possa estar se repetindo nos próximos anos para a localidade, ou se o efeito é passageiro, como afirma Christofoletti (1993), que mudanças de curto prazo podem ocorrer, sem que haja necessariamente mudanças climáticas.

Ressalta-se que o clima não é estático, e o comportamento do tempo atmosférico em um dado local passa por constantes processos de modificações naturais durante períodos suficientemente longos, devido às interações com outros fatores como altitude, latitude, disponibilidade hídrica, intensidade de radiação solar incidente, vegetação e relevo, fazendo-se necessário a elaboração 
de planos de uso e manejo adequado dos recursos naturais principalmente no período de estiagem.

\section{CONCLUSÃO}

A análise dos índices de precipitação e temperatura do ar no município de Diamantino durante o período de 31 anos permitiu observar que:

1- A média anual de temperatura do ar no período em estudo foi $25,3^{\circ} \mathrm{C}$;

2- A temperatura média do ar variou entre um mínimo de $22,6^{\circ} \mathrm{C}$, mês de julho, e um máximo de $27,0^{\circ} \mathrm{C}$, mês de outubro;

3- A média anual de precipitação foi de $1791,1 \mathrm{~mm}$ durante o período de estudo;

4- As médias mensais de precipitações oscilaram entre o inverno e o verão, com mínima de $10,7 \mathrm{~mm}$, no mês de julho, e máxima de $332,72 \mathrm{~mm}$, no mês de fevereiro, comportamento característico do bioma do cerrado;

5- Houve aumento na precipitação acumulada anual para os últimos $15 \mathrm{em}$ relação à média dos 31 anos analisados, e observou-se uma tendência de aumento de temperatura para os últimos três anos, necessitando de um acompanhamento constante destas análises para observar se este aumento permanecerá para os próximos anos, podendo causar impactos na agropecuária e conforto da população da região.

\section{REFERÊNCIAS}

AYOADE, J. O. Introdução à climatologia para os trópicos. (p. 286 e 287), Rio de Janeiro. Ed.Bertrand Brasil. 2010.

BARBARISI, B. F.; PILAU, F. G.; MARIN, F. R.; ASSAD, E. D.; PINTO, H. S. Estimativa da temperatura do ar para os estados de Mato Grosso do Sul, Mato Grosso, Goiás e Tocantins a partir do uso de imagens de Radar. In: Embrapa Informática Agropecuária-Resumo em anais de congresso (ALICE). In: Congresso Brasileiro de Meteorologia , 14, 2006, Florianópolis. Anais... Florianópolis: Sociedade Brasileira de Meteorologia, 2006. p. Não paginado, 2006.

BARROS, J. R. A chuva no Distrito Federal: o regime e as excepcionalidades do ritmo. 2003. xii, 221 f. Dissertação (mestrado) - Universidade Estadual Paulista, Instituto de Geociências e Ciências Exatas, 2003. Disponível em: $<$ http://hdl.handle.net/11449/86531>.

BOUERI, M. A.; LUNARDI, D. M. C. Avaliação de elementos agrometeorólogicos no cultivo do cravo-de-defunto (Tagetes sp.) em ambiente protegido e a campo. Revista Energia na Agricultura, v. 21, n. 3, 2006.

BRANCO, P. M. Elementos que caracterizam o clima. Disponível em: http://www. cprm. gov. br/publique/cgi/cgilua. exe/sys/start. htm, 2014.

BRASIL. Fundação Instituto Brasileiro de Geografia e Estatística -IBGE. Censo Demográfico, 2010. Disponível em:< http://cod. ibge. gov.br/2WXW2>. Acesso em: 14 jun. 2017. 
CHRISTOFOLETTI, A. Implicações geográficas relacionadas com as mudanças climáticas globais. Boletim de Geografia Teorética, Rio Claro, v. 23, n. 45-46, 1993, p. 18-31.

CONTI, J. B. Considerações sobre as mudanças climáticas globais. In: Revista do Departamento de Geografia, São Paulo, v. 16, 2005a, p.70-75. Disponível em:<https://doi.org/10.5418/RA2005.0202.0006>.Doi:10.5418/RA2005.0202.0006.

CUNHA, A. R.; MARTINS, D. Classificação climática para os municípios de Botucatu e São Manuel, SP. Irriga, v. 14, n. 1, p. 01, 2009. Disponível em:<http://dx.doi.org/10.15809/irriga.2009v14n1p01>. Doi: 10.15809 / i r r i g a . 2 009v14n1p01.

DALLACORT, R.; MARTINS, J. A.; INOUE, M. H.; FREITAS, P. S. L.; KRAUSE, W. Aptidão agroclimática do pinhão-manso na região de Tangará da Serra, MT. Revista Ciência Agronômica, v. 41, p.375-377, 2010.

DUBREUIL, V.; BARIOU, R.; PASSOS, M.; FERRAND, R.; NÉDÉLEC, V. Evolução da fronteira agrícola no Centro-Oeste de Mato Grosso: Municípios de Tangará da Serra, Campo Novo do Parecis e Diamantino. Área de Informação da Sede-Artigo em periódico indexado (ALICE), 2005.

HUSCHKE, R. E. Glossary of Meteorology, American Meteorological Society, Boston. 1959.

INMET - Instituto Nacional de Meteorologia . Banco de dados meteorológicos para ensino e pesquisa. Estações Convencionais. Disponível em:<http://www.inmet.gov.br/portal/index.php?

$\mathrm{r}=$ estacoes/estacoesconvencionais>.Acesso em: 07 nov. 2017.

INMET - Instituto Nacional de Meteorologia - Instrumentos Meteorológicos. Disponível em: <http://www.inmet.gov.br/portal/i nde $x$. p h $\mathrm{p}$ ?r= home/page\&page=instrumentos>. Acesso em: 12 de nov. de 2017.

KÖPPEN, W. Grundriss der Klimakunde: Outline of climate science. Berlin: Walter de Gruyter, 1931. 388p.

LIMA, C. B.; SANTOS, R. F.; SIQUEIRA, J. Análise da variação das temperaturas mínimas para Cascavel-PR ${ }^{1}$. Revista Brasileira de Energias Renováveis, v. 1, p. 1-21, 2012.

MARCUZZO, F. F. N.; CARDOSO, M. R. D.; FARIA, T. G. Chuvas no cerrado da região centro-oeste do Brasil: Análise histórica e tendência futura. Revista eletrônica Ateliê Geográfico, Goiânia - GO, v. 6, n. 2, p. 112-130, 2012. Disponível: <https://doi.org/10.5216/ag.v6i2.15234>.Doi:10.5216/ag.v6i2.15234. 
MEDEIROS, S. S.; CECÍLIO, R. A.; MELO JÚNIOR, J. C. F.; SILVA JUNIOR, J. L. C. Estimativa e espacialização das temperaturas do ar mínimas, médias e máximas na Região Nordeste do Brasil Estimation and spatialization of minimum, mean and maximum air temperatures for the Northeast region of Brazil. Revista Brasileira de Engenharia Agrícola e Ambiental-Agriambi, v. 9, n. 2, p. 247-255, 2005.

MENDONÇA, F.; DANNI-OLIVEIRA, I. M.; Climatologia: noções básicas e climas do Brasil. São Paulo. Oficina de texto. 2007.

MONTEIRO, C. A. F. Da necessidade de um caráter genético à classificação climática (Algumas considerações metodológicas á propósito do estudo do Brasil Meridional). Revista Geográfica, Rio de Janeiro, v. 31, n. 57, p. 29-44, 1962.

MOREIRA, P. S. P.; DALLACORT, R.; MAGALHÃES, R. A.; INOUE, M. H.; STIELER, M. C.; SILVA, D. J.; MARTINS, J. A. Distribuição e probabilidade de ocorrência de chuvas no município de Nova Maringá-MT. Revista de Ciências Agro-Ambientais, v. 8, n. 1, p. 9-20, 2010.

MOREIRA, P.; DALLACORT, R.; MAGALHÃES, R.; INOUE, M. Variabilidade anual, mensal e decendial da precipitação no município de Diamantino -MT. Universidade do Estado de Mato Grosso, Pró-Reitoria de Pesquisa e Pós Graduação, $2^{\text {a }}$ Jornada Científica da UNEMAT, Barra do Bugres- MT - 05 e 06 de Outubro de 2009., p.01, 2009.

NEVES, S. M. A. S.; NUNES, MARIA C. M.; NEVES, RONALDO J. Caracterização das condições climáticas de Cáceres/MT-Brasil, no período de 1971 a 2009: subsídio às atividades agropecuárias e turísticas municipais. Boletim goiano de geografia, v. 31, n. 2, 2011. Disponível em: < https://www. revistas.ufg.br/bgg/ article/download/16845 /10255>. Acesso em: 02 mar. de 2018. Doi: 10.5216/bgg.V31i2.16845.

PEREIRA, O.; NOVAIS, J.; SOUZA, R.; BIUDES, M.; MACHADO, N. Temperatura e Umidade Relativa do Ar por Psicrômetros de Ventilação Forçada. Ensaios e Ciência: C. Biológicas, Agrárias e da Saúde, v. 21, n. 3, p.183-186,2018. Disponível: <http://pgsskroton.com.br/seer/index.php/ensaio eciencia/article/vie w / 5145>. Acesso em: 12 mar. de 2018. Doi: 10.17921/1415-6938.2017v21n3p183186.

PINTO, E. J. A.; AZAMBUJA, A. M. S.; FARIAS, J. A. M.; SALGUEIRO, J. P. B.; PICKBRENNER, K. (Coords.). Atlas pluviométrico do Brasil: isoietas mensais, isoietas trimestrais, isoietas anuais, meses mais secos, meses mais chuvosos, trimestres mais secos, trimestres mais chuvosos. Brasília: CPRM, v. 1, 2011. Disponível em: < http://www.cprm.gov.br/publique/Hidrologia/Mapas-ePublicacoes/Atlas-Pluviometrico-do-Brasil-1351.html>. Acesso em: 08 nov. de 2017. 
RAMOS, H. C.; DALLACORT, R.; SANTI, A.; JUNIOR, S. S.; QUEIROZ, T. M. Precipitação pluvial de Diamantino-MT em anos de ocorrências de El niño, La niña e neutros. Revista Brasileira de Meteorologia, v.30, p.72-74, 2015. Disponível em: $\quad$ <ttp://www.scielo.br/pdf/rbmet/v30n1/0102-7786-rbmet-30-0100071.pdf>. Acesso em: 10 fev. de 2018. Doi:10.1590/0102-778620120477.

ROLIM, G. S.; CAMARGO, M. B. P.; LANIA, D. G.; MORAES, J.F.L. Classificação climática de Köppen e de Thornthwaite e sua aplicabilidade na determinação de zonas agroclimáticas para o estado de São Paulo. Bragantia, v. 66, n. 4, 2007. Doi: 10.1590/S0006-7052007000400022.

SOUSA, S. A. V.; PERES, F. C. Programa computacional para simulação da ocorrência de veranicos e queda de rendimento. Pesquisa Agropecuária Brasileira, v. 33, n. 12, p. 1951-1956, 1998.

VIANELLO, R. L. Maio 2011. Livreto: A Estação Meteorológica e seu Observador: Uma parceria secular de bons serviços prestados à humanidade. Instituto Nacional de Meteorologia - INMET. Disponível em: $<$ http://www .inmet. $\mathrm{g} \quad \mathrm{o} \quad \mathrm{v}$. $\mathrm{r}=$ home/page\&page=publicacoes $>$. Acesso em: 12 jan de 2018. 